\title{
Presepsin u akutnim i hroničnim poremećajima bubrežne funkcije
}

Zoran Gluvić1, Bojan Mitrović ${ }^{1}$, Andrijana Kulić ${ }^{2}$ Ana Strugar ${ }^{2}$, Vesna Libek $^{2}$

${ }^{1} \mathrm{KBC}$ Zemun, Klinika za internu medicinu, Odeljenje internističke intenzivne nege i Služba endokrinologije

${ }^{2} \mathrm{KBC}$ Zemun, Služba za transfuziologiju

Glikoprotein CD14 je komponenta urođene imunosti. Postoji u dve forme, membranskoj (mCD14) i solubilnoj (sCD14). sCD14 nastaje ili indirektno, od mCD14, ili direktno, sekrecijom iz intraćelijskih vezikula fagocita (pod efektom katepsina D). sCD14 se predominantno sekretuje iz jetre i monocita ${ }^{1,2}$. mCD14 je eksprimiran na površini makrofagnih, neutrofilnih i dendritičnih ćelija, a prevashodno služi kao specifični visokoafinitetni koreceptor za lipopolisaharid (LPS) gram negativnih bakterija. Naime, mCD14 zajedno sa toll-like receptorom 4 (TLR4) i MD-2, služi za prepoznavanje i vezivanje kompleksa LPS/lipopolisaharidnog vezujućeg proteina bakterija. mCD14 se oslobađa iz kompleksa u cirkulaciju i postaje sCD14, a pod efektom serumskih proteaza nastaje sCD14 podtip (engl. sCD14 subtype, sCD14-ST). sCD14-ST je presepsin (PSP) ${ }^{3-5}$.

Indukcija PSP je brza, te se u cirkulaciji detektuje već nakon $2 \mathrm{~h}$ od značajnog infektivnog prodora, dok je u slučajevima C-reaktivnog proteina (CRP) i prokalcitonina (PCT) ona značajno sporija ( $>4-6 \mathrm{~h}$ za CRP, tj. 8-24h za PCT) ${ }^{6-8}$. Nivo PSP korelira sa APACHE II skorom i prognozom odnosno ishodom bolesti ${ }^{9,10}$. Ukupna senzitivnost (Se) od $83 \%$, specifičnost (Sp) od 78\% i dijagnostička preciznost od $88 \%$, ukazuje da vrednost izmerenog nivoa PSP omogućava relativno bezbedno razlikovanje nespecifičnog sistemskog inflamatornog odgovora (engl. Systemic Inflammatory Response Syndrome, SIRS) od sepse. Ipak, PSP ne bi trebalo koristiti samostalno za potvrdu ili isključenje septičnog stanja, već u kombinaciji sa drugim biomarkerima sistemske infekcije i isključivo u kliničkom kontekstu ${ }^{11}$. Studije su pokazale da je najsenzitivniji cut-off nivo za razlikovanje bakterijske od nebakterijske sistemske infekcije 600pg/ml, sa Se 79-87\% i Sp 61-81\%. Senzitivnost dijagnostičke vrednosti PSP očekivano raste sa porastom njegovog nivoa. Visoki nivoi PSP su, pored ostalih, ominozan klinički znak - ukazuju na verovatnu lošu prognozu bolesti ${ }^{12,13}$. U kombinaciji sa drugim markerima sistemske infekcije (CRP, PCT, engl. soluble triggering receptor expressed on myeloid cells 1, sTREM-1), koristan je u regrutovanju obolelih za prijem u bolnicu, kao i za prijem u jedinice intenzivnog lečenja (JIL) ${ }^{14}$. PSP ima relativno slabu samostalnu sposobnost predikcije bakterijemije i potrebe za hospitalizacijom. Pored toga, PSP ne nudi značajnu superiornost $u$ odnosu na druge biomarkere sistemske infekcije, poput CRP i PCT ${ }^{15}, 16$.

\section{PSP i akutna bubrežna insuficijencija (ABI)}

PSP (13kDa) se filtruje bubrezima i nivo u krvi značajno zavisi od bubrežne funkcije. Relativno je mali broj studija koje su ispitivale korisnost određivanja PSP kod obolelih od ABI. Nivo PSP je značajno povišen kod septičnih bolesnika bez ABI, kao i obolelih od blažih formi ABI (RI po RIFLE ABI klasifikaciji) u poređenju sa ne-septičnim grupama ${ }^{17}{ }^{18}$. Nivoi PSP u krvi mogu biti pouzdan indikator sepse ne samo kod ne-ABI bolesnika, već i kod obolelih sa nižim stadijumima ABI, ali svakako ne i kod obolelih sa višim stadijumima ABI, poput „FLE“ stadijuma po RIFLE ABI klasifikaciji18.

Kontinuirana zamena bubrežne funkcije (engl. Renal Replacement Therapy, RRT) se sve više koristi za tretman ABI u JIL. Eliminacija CRP i PCT je značajna tokom RRT. Klirens PSP može biti čak i veći od očekivanog, iz razloga što se ovaj mali molekul može zaglaviti na visoko adsorptivnim membrana RRT aparata ${ }^{19}$. Studija koja je određivala nivo PSP pre i posle RRT, pokazala je da su njegovi nivoi bili gotovo identični. Isti tip dijalizne membrane (u ovoj studiji polisulfonska) je korišćen kod svih ispitanika, tako da je efekat RRT sa polisulfonskom embranom neznatan sa aspekta uticaja na nivo PSP. Kod obolelih sa poremećajem bubrežne funkcije pojedinačno merenje PSP nije od koristi za dijagnozu sepse, ali se kontinuirana merenja PSP u vremenu, preporučuju za razlikovanje sepse od ne-sepse, a u slučaju sepse i njenog toka ${ }^{20}$. 


\section{PSP i hronična bubrežna insuficijencija (HBI)}

Smanjena jačina glomerulske filtracije (engl. Glomerular Filtration Rate, GFR) uzrokuje povećanje nivoa PSP u krvi, te stoga cut-off vrednosti PSP kod obolelih sa bubrežnom insuficijencijom treba obazrivo tumačiti ${ }^{18,20}$. Nivoi PSP su povišeni kod velikog broja obolelih sa GFR $<60 \mathrm{ml} / \mathrm{min} . / 1.73 \mathrm{~m}^{2}$. Pored toga, nivoi PSP su značajno povišeni kod obolelih od HBI tretiranih hemodijalizom (HD), ali i negativno korelišu sa GFR kod obolelih od HBI koji nisu na HD tretmanu ${ }^{21}$.

Nivoi PSP značajno opadaju nakon HD. To ukazuje da molekuli PSP mogu difundovati i biti isfiltrovani do određenog nivoa pomoću ,high-flux" HD, ali su ti nivoi i dalje visoki nakon HD. Pretpostavlja se da su povišeni nivoi PSP nakon HD rezultat njegovog smanjenog klirensa HD-om i/ili povišene produkcije PSP22. Evaluacija nivoa PSP kod HBI bolesnika zahteva posebnu pažnju. Drugačiji cut-off nivoi PSP su neophodni za postavljanje dijagnoze sepse kod HBI bolesnika ${ }^{22}$. Povišeni nivoi kreatinina su najjači prediktori nivoa PSP kod obolelih u JIL ${ }^{23}$.

\section{Zaključak}

Za postavljanje dijagnoze sepse, najpouzdanije je određivanje PSP u kombinaciji sa drugim markerima sistemske infekcije. Pojedinačno merenje je često bez značaja, tako da je kontinuirano merenje u vremenu, sa trendovima pada ili porasta nivoa markera sistemske infekcije, daleko informativnije. Nivo PSP značajno zavisi od GFR. Kod obolelih od ABI, PSP je solidan pokazatelj sistemske infekcije do težih i prologiranih stadijuma ABI. Kod obolelih od HBI, tumačenje vrednosti PSP je veoma spekulativno, te postoji potreba za definisanjem novih cut-off vrednosti za PSP kod ovih bolesnika. Kod oblelih pod tretmanom HD, pokazan je različit klirens PSP sa različitim dijaliznim membranama. Svakako, nivo PSP se po HD vraća na pređašnji nivo, koji je inače povišen.

\section{Reference}

1. Zanoni I, Granucci F. Role of CD14 in host protection against infections and in metabolism regulation. Front Cell Infect Microbiol 2013; 3: 32.

2. Meuleman P, Steyaert S, Libbrecht L, Couvent S, Van Houtte F, Clinckspoor F et al. Human hepatocytes secrete soluble CD14, a process not directly influenced by HBV and HCV infection. Clin Chim Acta 2006; 366: 156-62.

3. Zhang J, Hu Z-D, Song J, Shao J. Diagnostic value of presepsin for sepsis. Medicine (Baltimore) 2015; 94(47): e2158.

4. Mussap M, Noto A, Fravega M, Fanos V. Soluble CD14 subtype presepsin (sCD14-ST) and lipopolysaccharide binding protein (LBP) in neonatal sepsis: new clinical and analytical perspectives for two old biomarkers. J Matern Fetal Neonatal Med 2011; Suppl 2: 12-4.

5. Qi Z, Wei W, Zhang XC. Presepsin as a novel sepsis biomarker. World J Emerg Med 2014; 5: 16-9.

6. Chenevier-Gobeaux C, Bardet V, Poupet H, Poyart C, Borderie D, Claessens YE. Presepsin (sCD14-ST) secretion and kinetics by peripheral blood mononuclear cells and monocytic THP-1 cell line. Ann Biol Clin (Paris) 2016; 74(1): 93-7.

7. Okamura Y, Yokoi H. Development of a point-of-care assay system for measurement of presepsin (sCD14-ST). Clin Chim Acta 2011; 412: 2157-61.

8. Volanakis JE. Human C-reactive protein: expression, structure, and function. Mol Immunol 2001; 38: $189-97$.

9. Shozushima T, Takahashi G, Matsumoto N, Kojika M, Okamura Y, Endo S. Usefulness of presepsin (sCD14-ST) measurements as a marker for the diagnosis and severity of sepsis that satisfied diagnostic criteria of systemic inflammatory response syndrome. J Infect Chemother 2011; 17: 764-9.

10. Jacobs L, Wong HR. Emerging infection and sepsis biomarkers: will they change current therapies? Expert Rev Anti Infect Ther 2016; 14: 929-41.

11. Zheng Z, Jiang L, Ye L, Gao Y, Tang L, Zhang M. The accuracy of PSP for the diagnosis of sepsis from SIRS: a systematic review and meta-analysis. Ann Intensive Care 2015; 5: 48.

12. Giavarina D, Carta M. Determination of reference interval for PSP, an early marker for sepsis. Biochem Med (Zagreb) 2015; 25: 64-8.

13. Ulla M, Pizzolato E, Lucchiari M, Loiacono M, Soardo F, Forno D et al. Diagnostic and prognostic value of presepsin in the management of sepsis in the emergency department: a multicenter prospective study. Crit Care 2013; $17: \mathrm{R} 168$. 
14. Liu Y, Hou JH, Li Q, Chen KJ, Wang SN, Wang JM. Biomarkers for diagnosis of sepsis in patients with SIRS: a systematic review and meta-analysis. SpringerPlus 2016; 5: 2091.

15. Wu CC, Lan HM, Han ST, Chaou CH, Yeh CF, Liu SH et al. Comparison of diagnostic accuracy in sepsis between presepsin, procalcitonin and C-reactive protein: a systematic review and meta-analysis. Ann Intensive Care 2017; 7: 91.

16. Claessens YE, Trabattoni E, Grabar S, Quinquis L, Der Sahakian G, Anselmo M et al. Plasmatic presepsin (sCD14-ST) concentrations in acute pyelonephritis in adult patients. Clin Chim Acta 2017; 464: 182-8.

17. Bellomo R, Ronco C, Kellum JA, Mehta RL, Palevsky P; Acute Dialysis Initiative workgroup. Acute renal failure- definition, outcome measures, animal models, fluid therapy and inflammation technology needs: the second international consensus conference of the acute dialysis quality initiative (ADQI) group. Crit care 2004; 8: R204-12.

18. Nakamura Y, Ishikura H, Nishida T, Kawano Y, Yuge R, Ichiki R et al. Usefulness of prsepsin in diagnosis of sepsis in patients with or without acute kidney injury. BMC Anesthesiology 2014; 14: 88.

19. Honore PM, Jacobs R, Hendrickx I, De Waele E, Van Gorp V, Spapen HD. Presepsin and sepsis-induced acute kidney injury treated with continuous renal replacement therapy: will another promising biomarker bite the dust? Crit Care. 2015; 19: 428.

20. Kotera A, Sagishima K, Tashiro T, Niimori D, Kamohara H, Kinoshita Y. A validation of presepsin levels in kidney dysfunction patients: four case reports. J Intensive Care 2014; 2: 63.

21. Chenevier-Gobeaux C, Trabattoni E, Roelens M, Borderie D, Claessens YE. Presepsin (sCD14-ST) in emergency department: the need for adapted threshold values? Clin Chim Acta 2014; 427: 34-6.

22. Nagata T, Yasuda Y, Ando M, Abe T, Katsuno T, Kato S et al. Clinical impact of kidney function on presepsin levels. PLoS One 2015; 10: e0129159.

23. Masson S, Caironi P, Fanizza C, Thomae R, Bernasconi R, Noto A et al. Circulating presepsin (soluble CD14 subtype) as a marker of host response in patients with severe sepsis or septic shock: data from the multicenter, randomized ALBIOS trial. Intensive Care Med 2015; 41: 12-20.

Autor za korespondenciju: Zoran Gluvić,

Odeljenje internističke intenzivne nege i Služba endokrinologije KBC Zemun,

Vukova 9, Zemun; tel. 3772 759;

e-mail: zorangluvic@yahoo.com 